\title{
1 Sorption, Photodegradation, and Chemical 2 Transformation of Naproxen and Ibuprofen 3 in Soils and Water
}

4 Vijay M. Vulava ${ }^{1,3}$, Wendy Cory ${ }^{2}$, Virginia Murphey ${ }^{1}$, 5 Candice Ulmer ${ }^{2}$

$6{ }^{1}$ Department of Geology and Environmental Geosciences, College of Charleston, 66 George Street,

7 Charleston, SC 29424

$8{ }^{2}$ Department of Chemistry and Biochemistry, College of Charleston, 66 George Street, Charleston, SC $9 \quad 29424$

${ }^{3}$ Corresponding Author. Address: College of Charleston, Department of Geology and Environmental

11 Geosciences, 66 George St., Charleston, SC 29424, Phone: +1.843.953.1922, Fax: +1.843.953.5446,

12 email: $\underline{\text { VulavaV@cofc.edu }}$

Keywords: Naproxen; Ibuprofen; Pharmaceutical Chemicals; Soil sorption; Photodegradation;

15 Transformation; Organic Matter 


\section{Abstract}

26 Pharmaceutically active compounds (PhACs) are released into the environment where they

27 undergo soil sorption, photodegradation, and chemical transformation into structurally similar

28 compounds. Here we report on studies of naproxen (NAP) and ibuprofen (IBP), two widely-used

29 nonsteroidal anti-inflammatory drugs (NSAIDS), in soils and water. Organic matter (OM) was

30 observed to play an important role in each of these processes. Sorption was observed to be

31 stronger and nonlinear in higher OM soils while weaker but still significant in lower OM, higher

32 clay soils; the amphiphilic nature of these two PhACs combined with the complex charged and

33 nonpolar surfaces available in the soil was observed to control the sorption behavior. Simulated

34 solar photodegradation rates of NAP and IBP in water were observed to change in the presence

35 of humic acid or fulvic acid. Structural analogs of each compound were observed as the result of 36 chemical transformation in both photoexposed aqueous solutions and non-photoexposed soil.

37 Two of these transformation products were detected as both soil and photo transformation

38 products for both PhACs. OM was observed to influence the chemical transformation of both 39 pharmaceuticals. 
40 Graphical Abstract:

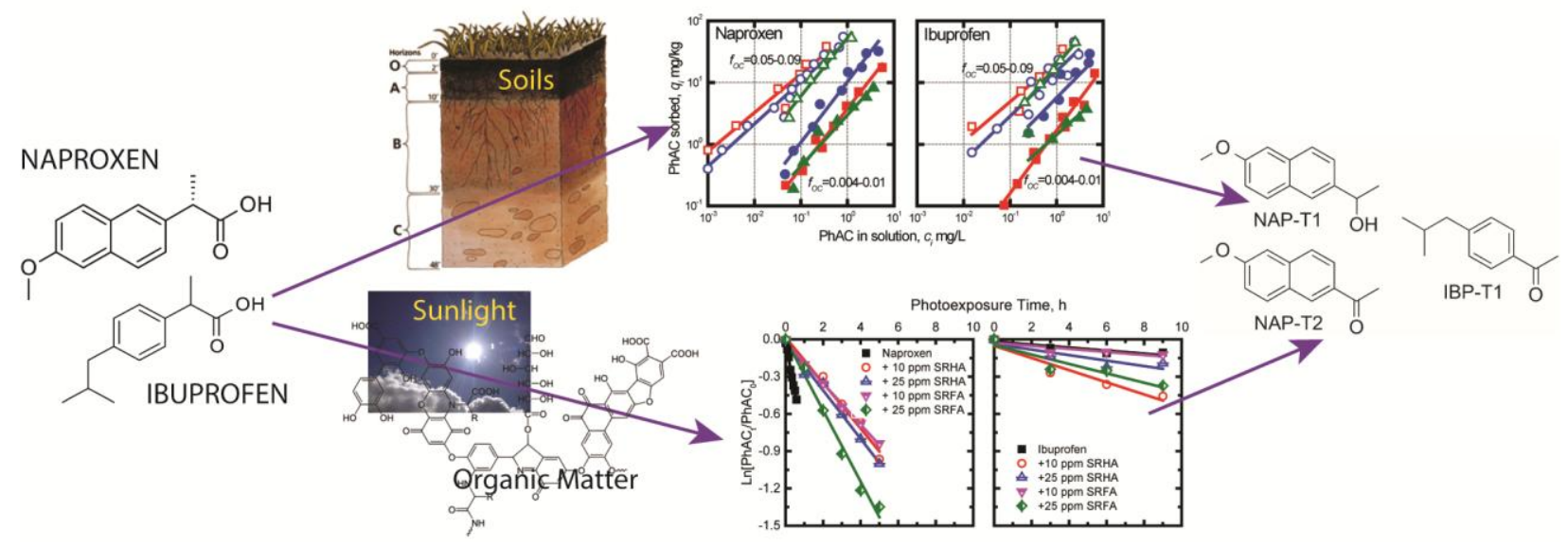

41

42 Capsule:

43 Organic matter present in water and soil played a critical role in sorption, photodegradation, and

44 chemical transformation of ibuprofen and naproxen. 
46 The twentieth century saw tremendous growth in the development, availability, and use of

47 pharmaceuticals to treat disease. As a result, trace levels of pharmaceutically active compounds

48 (PhACs) are currently found in municipal drinking water and natural streams around the world

49 (Barnes et al., 2008; Benotti et al., 2008; Cunningham, 2008; Focazio et al., 2008; Jelić et al.,

50 2012; Kolpin et al., 2002; Lapworth et al., 2012; Li, 2014). PhACs enter natural water systems

51 after passing through wastewater treatment plants that have proven to be relatively inefficient at

52 removing them (Cunningham, 2008; Khetan and Collins, 2007; Li, 2014; Snyder et al., 2003;

53 Ternes et al., 2004). Measured concentrations of PhACs in natural waters are typically well

54 below medical dosage levels, but studies of ecosystem risk have indicated adverse effects to both

55 aquatic and non-aquatic organisms (Daughton and Ternes, 1999; Halling-Sorenson et al., 1998;

$56 \quad$ Khetan and Collins, 2007).

57 Because of their continuous use and release from wastewater treatment plants, PhACs are 58 considered to be pseudo-persistent contaminants (Daughton and Ternes, 1999). Once entering 59 the environment, they can persist either in their original form or as structurally similar 60 transformation products (Daughton and Ternes, 1999; Snyder et al., 2003). Two of the 61 predominant processes that determine the environmental fate of PhACs are (1) sorption to soils 62 and sediments and (2) photodegradation in aquatic environments. Both can result in the 63 formation of $\mathrm{PhAC}$ transformation products.

64 Soils and sediments are the ultimate repository for PhACs discharged into the environment. The 65 binding of PhACs to natural soils and sediment has been the subject of recent reports (Loffler et 66 al., 2005; Matamoros and Bayona, 2006; Thiele-Bruhn, 2003; Tolls, 2001; Yamamoto et al., 
67 2009). The chemical structure of the $\mathrm{PhAC}$, the texture of the soil, and the presence of reactive 68 groups in the soils such as organic matter and mineral oxide surfaces are critical in influencing 69 the binding of PhACs to soils (Loffler et al., 2005). Other factors such as soil exchange capacity 70 and soil solution $\mathrm{pH}$ are also important (Schwarzenbach et al., 2003). Previous studies have 71 looked at sorption of ibuprofen and reported lower soil sorption coefficients for this acidic PhAC 72 (Loffler et al., 2005) especially as compared to basic PhACs (Yamamoto et al., 2009). There is 73 evidence that PhACs can be attenuated during transport by soil materials into groundwater from 74 surface water (Bradley et al., 2014). Degradation occurring in the soil environment has been 75 observed to result in PhAC transformation products due to chemical transformations of the 76 parent compound (Dodgen et al., 2014; Li et al., 2014).

77 Sunlight exposure often leads to the photodegradation of PhACs present in surface waters via 78 both direct and indirect processes. Direct photodegradation occurs when the UV absorption 79 spectrum of the PhAC (at environmentally relevant $\mathrm{pH}$ levels) overlaps with the solar spectrum 80 (>290 nm). Indirect photodegradation can occur in natural waters when dissolved organic matter 81 absorbs sunlight, producing reactive oxygen species (including singlet oxygen, the superoxide 82 ion, and hydroxyl radicals) and/or is excited to the triplet state, ${ }^{3} \mathrm{DOM}^{*}$, which can then transfer 83 energy to the PhAC via triplet-triplet energy transfer (TTET) (Cooper et al., 1989; Guerard et al., 84 2009). At the same time, DOM can inhibit photoexposure (Boreen et al., 2004; Walse et al., 85 2004) via sunlight filtration as well as by quenching photochemical reactions. Sunlight exposure 86 has been found to result in PhAC transformation products including those that are more 87 persistent and more ecotoxic (Fatta-Kassinos et al., 2011).

88 Naproxen and ibuprofen (NAP and IBP, Fig. 1) are two drugs widely used for treatment of pain 89 and inflammation. Studies have shown that after human use, 72\% of the excreted NAP (Runkel 
et al., 1972) is present as either the original or a conjugated form (which is easily cleaved in

91 water to release the original pharmaceutical). IBP is more extensively metabolized; studies

92 indicate that 15\% (Food and Drug Administration, 2007) of excreted IBP is in the free or

93 conjugated form. Both PhACs have been detected globally in water samples, including sewage

94 treatment plant (STP) influent at $3.2 \mathrm{ppb}$ NAP (Yu et al., 2006) and 7.1 ppb IBP (Pal et al.,

95 2010), and in German rivers (Ternes, 1998) at up to 0.39 ppb NAP and 0.53 ppb IBP.

Log $\mathrm{K}_{\mathrm{ow}}=3.2$
$\mathrm{Log}_{\mathrm{ow}}=1.7$

96

97 NAP and IBP are both amphiphilic molecules with aromatic (nonpolar) and carboxylic acid 98 (polar/anionic, pH-dependent) functional groups (Fig. 1). The log octanol-water partitioning 99 coefficients $\left(\log K_{\mathrm{OW}}\right)$ for NAP (3.2) and IBP (3.6) indicate that both are somewhat hydrophobic.

100 Both PhACs also have a carboxylic acid group that is deprotonated at environmentally-relevant 
$101 \mathrm{pH}$ levels (5-8) and so are primarily in anionic, conjugate base forms in the aquatic and soil 102 environments. The $\log D_{\mathrm{OW}}$ values (NAP, 1.7; IBP, 2.2) take this $\mathrm{pH}$-dependent ionization into 103 consideration and indicate that while the deprotonated forms of NAP and IBP are less 104 hydrophobic than their neutral forms, they still maintain some of their nonpolar character. This 105 amphiphilic nature suggests potentially complex interactions between NAP and IBP with natural 106 sorption surfaces, including SOM, mineral surfaces, and in tissues of aquatic organisms.

107 In this study we investigated the soil sorption, solar photodegradation, and chemical 108 transformation of NAP and IBP as part of an assessment of the environmental fate of these 109 PhACs. Organic matter was observed to affect each of these processes. Sorption studies were 110 conducted in soil samples with different $\mathrm{OM}$ and clay mineral contents. Based on previous 111 studies, we hypothesized that NAP and IBP would preferentially sorb to organic-rich soils 112 because of their nonpolar moieties. Photodegradation of NAP and IBP, such as that which would 113 occur in surface waters, was investigated with and without the addition of Suwanee River Humic 114 Acid (SRHA) and Fulvic Acid (SRFA); we hypothesized that these reactive fractions of DOM 115 would aid in the photodegradation of IBP, which does not directly absorb sunlight, but would 116 reduce the rate of photodegradation of NAP, which does. NAP and IBP were monitored in all 117 solutions by high performance liquid chromatography (HPLC); transformation products were 118 detected and identified by liquid chromatography with tandem mass spectrometry (LC-MS/MS). 
122 Sorption studies were performed on clean soils collected from Francis Marion National Forest, a

123 US Forest Service-managed pristine forested watershed near Charleston, SC, USA. A- and B124 horizon soils were collected from areas with no apparent sources of anthropogenic 125 contamination. In all cases, the A-horizon soils were collected from near-surface to a depth of 126 approximately $15 \mathrm{~cm}$ below ground surface (b.g.s.). The B-horizon soils were collected from a 127 depth of $25-40 \mathrm{~cm}$ b.g.s. A- and B-horizon soils used in all experiments were collected at the 128 same location for each soil series sampled at this site. These soils were air-dried for $24 \mathrm{~h}$ in a 129 laboratory at $21^{\circ} \mathrm{C}$ and $60 \%$ relative humidity. After $24 \mathrm{~h}$, large clods were gently broken into 130 smaller pieces by hand and roots and rock fragments were removed. Finally, the soil samples 131 were homogenized, stored in plastic bags, and sealed in air-tight plastic containers pending 132 further use.

\subsection{Soil Characterization:}

134 Each soil was characterized for organic matter content (OM) by a thermal oxidation method 135 (Swift, 1996), particle size fractionation using both sieving and a particle size analyzer (Gee and 136 Or, 2002), and soil $\mathrm{pH}$ in de-ionized water or $10 \mathrm{mM} \mathrm{CaCl} \mathrm{Cl}_{2}$ solutions (Thomas, 1996). 137 Predominant minerals that made up the clay-sized fractions of the soils were determined using 138 reflectance spectroscopy (Biehl and Stoner, 1985; Clark, 1999; White and Roth, 1986) and a 139 spectroradiometer (LabSpec benchtop analyzer, ASD, Boulder, CO). Dried (105 $\left.{ }^{\circ} \mathrm{C}, 24 \mathrm{~h}\right)$ and hydrogen peroxide treated (for OM removal) clay-sized fractions $(<63 \mu \mathrm{m})$ of all soil samples 
141 were measured for reflectance in the near-infrared range $(0.7-2.5 \mu \mathrm{m})$. The measured spectra was

142 matched with USGS Digital Spectral Library (Clark et al., 2003) using ENVI software 143 environment (Excelis, Inc., Boulder, CO) to make qualitative assessments of predominant 144 minerals present in the soils.

\subsection{Sorption Studies:}

146 The reactivity of NAP and IBP (Sigma Aldrich, St. Louis, MO) in different soils was assessed

147 using batch sorption experiments. In these experiments, a known concentration of NAP or IBP 148 was spiked into a pre-cleaned Pyrex ${ }^{\mathrm{TM}}$ media storage bottle containing $0.5-10 \mathrm{~g}$ of soil and 50$149500 \mathrm{~mL}$ of $10 \mathrm{mM} \mathrm{CaCl}_{2}$ solution prepared in deionized water. The soil:solution ratio (ranging 150 from 1:5 to 1:1000) was adjusted based on expected strength of sorption (e.g., lower soil:solution 151 ratio was used when sorption was expected to be strong and vice versa). This method allowed the 152 final equilibrium concentration of NAP or IBP to be within $20-80 \%$ of initial concentration 153 applied to the soil solution (Vulava et al., 2000). The $\mathrm{pH}$ levels of both initial and final solutions 154 were measured. Sample blanks were also run in a setup identical to the batch sorption 155 experiments, but with no soil included in the batch reactor. Batch reactor experiments using 156 high-OM soils were also performed in a dark box to exclude ambient indoor light.

157 The bottles were shaken in a reciprocating shaker for $7 \mathrm{~d}$ in the dark to ensure equilibrium 158 between soil and PhACs. This equilibration time was determined from initial kinetic sorption 159 experiments in which a constant concentration $(10$ or $20 \mathrm{mg} / \mathrm{L})$ of $\mathrm{PhAC}$ solution $(100 \mathrm{~mL})$ was 160 applied to several bottles containing $10 \mathrm{~g}$ of soil; bottles were removed for sampling at specified 161 time intervals $(2 \mathrm{~h}$ to $14 \mathrm{~d}$ ). To separate soil from the bulk solution, the samples were filtered 162 using $0.45 \mu \mathrm{m}$ Millipore ${ }^{\mathrm{TM}}$ Millex $^{\mathrm{TM}}$ PES syringe filters (recovery > 98\%). The filtrate was 
163 analyzed for the PhAC and any transformation products using HPLC as described in a following 164 section.

\subsection{Photoexposure Studies:}

$166 \mathrm{PhAC}$ solutions of $500 \mathrm{ppb}, 50 \mathrm{ppb}$ or $5 \mathrm{ppb}$ of NAP and IBP, with and without the addition of 10 167 or 25 ppm Suwannee River Fulvic Acid Standard II (SRFA) or Humic Acid Standard II (SRHA) 168 (IHSS, St. Paul MN) were prepared for photoexposure studies. All solutions were prepared in 5 $169 \mathrm{mM}$ phosphate buffer solution $(\mathrm{pH}=7.0)$ in distilled water and sonicated to ensure full

170 dissolution before photoexposure. Solutions were stored in the dark in amber glass bottles at $5{ }^{\circ} \mathrm{C}$ 171 until photoexposure. Control samples were stored in the dark at ambient room temperature.

172 Photoexposure was carried out using a solar simulator photoreactor (LuzChem SolSim, Ottawa, 173 Ontario, Canada) at 400,000 Lux, calibrated to match the standard AM1.5 spectrum, with 174 diffuser table. Solutions were contained in quartz vials $(3.5 \mathrm{~mL})$ with PTFE-lined septa (NSG 175 Precision Cells Inc., Farmingdale, NY) during photoexposure. Vials were tightly capped to 176 prevent the release of volatile phototransformation (PT) products. At predetermined time points, 177 aliquots of each aqueous solution $(0.3 \mathrm{~mL})$ were transferred via $0.5 \mathrm{~mL}$ glass syringes (Hamilton, 178 Reno NV) into individual amber glass HPLC vials for HPLC analysis in the following manner: 179 the syringe pierced the septum on the quartz vial, an $0.3 \mathrm{~mL}$ aliquot was withdrawn, and then the 180 syringe pierced the septum on the HPLC vial to avoid sample contact with open air and the 181 potential loss of PT products due to volatilization. Each sample was prepared in triplicate to 182 ensure reproducibility. Temperature change during photoexposure was observed to be negligible. 
184

185

186

187

188

189

190

191

192

193

194

195

196

197

198

HPLC analysis was carried out on an Agilent LC 1200 with diode array detection. Separation was achieved with a C8 column (Agilent Eclipse Plus, $4.6 \times 150 \mathrm{~mm}, 3.5 \mu \mathrm{m}$ particle size) using the following $1.0 \mathrm{~mL} / \mathrm{min}$ mobile phase gradient: $\mathrm{t}=0-1 \mathrm{~min}, 55 \%$ buffer $(20 \mathrm{mM}$ formic acid, $\mathrm{pH}=3.0$ ): $45 \%$ acetonitrile; $\mathrm{t}=1-4 \mathrm{~min}$, gradient to $20 \%$ buffer: $80 \%$ acetonitrile; $\mathrm{t}=4-8 \mathrm{~min}$, isocratic hold at $20 \%$ buffer: $80 \%$ acetonitrile. The column was held at ambient temperature and allowed to re-equilibrate for 2 min between injections; an injection volume of $100 \mu \mathrm{L}$ was used. With these conditions, limits of detection of $\sim 1 \mathrm{pbb}$ for NAP and $\sim 10 \mathrm{ppb}$ IBP (both at $230 \mathrm{~nm}$ ) were achieved. Four wavelengths were monitored to ensure detection of all major transformation products: $214 \mathrm{~nm}, 230 \mathrm{~nm}, 254 \mathrm{~nm}$ and $280 \mathrm{~nm}$. The transformation products were preliminarily identified by comparison of retention times and UV absorbance spectra with standard solutions (1-(6-methoxy-2-naphthyl)ethanol, 2-acetyl-6-methoxynaphthalene, and 4-isobutylacetophenone, Alfa Aesar, Ward Hill, MA), followed by confirmation with atmospheric pressure chemical ionization - liquid chromatography - mass spectrometry (APCI-LC-MS/MS).

\subsection{APCI-LC-MS/MS Analysis:}

Confirmation of the identities of NAP and IBP transformation products was carried out using a Velos Pro LC-MS (Thermo Scientific) system with a heated atmospheric pressure chemical ionization (APCI) source. The isocratic LC method included a C8 column (Agilent Eclipse Plus, $4.6 \times 150 \mathrm{~mm}, 3.5 \mu \mathrm{m}$ particle size) with a mobile phase of $60 \%$ aqueous $0.1 \%$ formic acid and $40 \%$ acetonitrile with $0.1 \%$ formic acid, mobile phase flow rate $1.0 \mathrm{~mL} / \mathrm{min}$, and an injection volume of $1 \mu \mathrm{L}$. 
204 APCI parameters included source heater/vaporizer temperature of $350{ }^{\circ} \mathrm{C}$, sheath gas flow rate of

20560 (arb units), auxiliary gas flow rate of 20 (arb units), sweep gas flow rate of 5 (arb units), 206 discharge current of $5.00 \mu \mathrm{A}$, and capillary temperature of $200{ }^{\circ} \mathrm{C}$. Other settings for the ion trap 207 and APCI were optimized using LTQ Tune software.

208 The MS/MS analysis was carried out at a normalized collision energy of $35 \%$ and $\mathrm{Q}=0.250$. 209 MS/MS data of soil and photoexposed samples was compared to that of standard materials.

\section{RESULTS AND DISCUSSION}

\subsection{Soil Sorption:}

213 The soils characterized in this study had disparate properties: OM content $0.4 \%$ to $9 \%\left(f_{\mathrm{OC}}=\right.$ 214 0.004-0.9), clay mineral content 6-20\%, and soil $\mathrm{pH} 4.5-6.5$. The clay mineral composition was 215 primarily kaolinite (up to $85 \%$ ) and smectite (up to $15 \%)$ with a small amount $(<0.5 \%)$ of $\mathrm{Fe}$ 216 oxides, primarily hematite with some goethite. In all cases, the A-horizon soils had higher $f_{\mathrm{OC}}$ 217 and lower clay content than the B-horizon soils. Recent studies have shown the organic matter is 218 comprised of diverse collections of humic substances and could be extremely variable within the 219 same soil (Sutton and Sposito, 2005). The structure of the OM in these soils was not 220 characterized. It was expected that the complex humic and fulvic acid fractions of the soil OM 221 would be the most chemically reactive due to the presence of numerous carboxylic acid, amine, 222 and alcohol functional groups within the aromatic fractions (Oades, 1989; Schwarzenbach et al., 223 2003). During sorption experiments, soil solution $\mathrm{pH}$ remained constant and approximately the 224 same as the soil $\mathrm{pH}( \pm 0.5)$ in this study. 


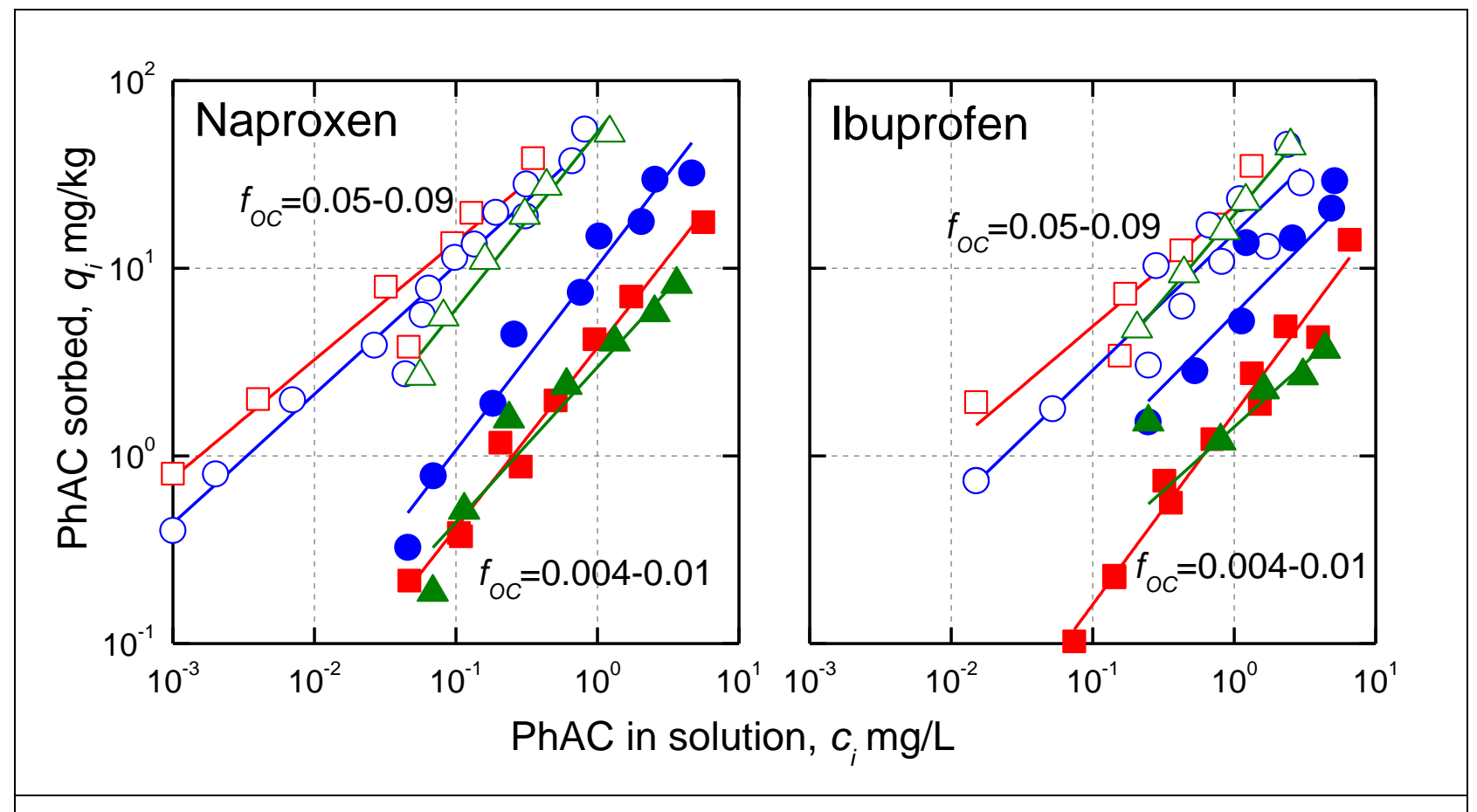

Figure 2: Sorption isotherms of naproxen and ibuprofen in A-horizon (hollow markers) and in B-horizon (solid markers). $f_{\mathrm{OC}}$ values correlate with the $\mathrm{OM}$ content in soils. Lines are Freundlich isotherm model fits for each set of isotherm data.

Both compounds sorbed more strongly to A-horizon soils than to the B-horizon soils. The

227 sorption isotherms (plot of $\mathrm{PhAC}$ in solution, $c_{i} \mathrm{mg} / \mathrm{L}$ vs. PhAC sorbed, $q_{i} \mathrm{mg} / \mathrm{kg}$, Fig. 2)

228 indicated a linear relationship in B-horizon soils, while a non-linear relationship was observed in

229 A-horizon soils due to stronger sorption at lower PhAC concentrations and weaker sorption at

230 higher concentrations (Fig. 2). However, in all cases, sorption was five to ten times stronger in

231 A-horizon soils as compared to that in B-horizon soils, indicating that SOM played a significant

232 role in binding both NAP and IBP to soil components. At the soil solution $\mathrm{pH}$, the deprotonated

233 carboxylic acid functional group (Fig. 1) of both PhACs likely adsorbed to charged portions

234 (protonated amines) of the SOM as well as to some amphoteric mineral oxide surfaces (e.g., Fe-,

235 Al-oxides) present in the soils (Kleber et al., 2007; Schwarzenbach et al., 2003). Sorption in B- 
236 horizon soils indicated that other mineral components play an important in sorption of NAP and 237 IBP (Stumm and Morgan, 1996). The deprotonated forms of NAP and IBP likely bonded with 238 the charged inorganic surfaces via simple electrostatic attraction or the stronger chemisorption 239 (Schwarzenbach et al., 2003). The soil solution $\mathrm{pH}$ also played a very important role in 240 influencing the charge on various soil components. At $\mathrm{pH} 5 \pm 0.2$, the predominantly deprotonated 241 NAP and IBP sorbed more strongly to the amphoteric Fe oxide surfaces than to the permanent 242 negatively charged clay mineral surfaces (Chiou, 2003; Figueroa and MacKay, 2005; Zhang and 243 Huang, 2007); the positive charge on these Fe oxides would have offered simple ligand exchange 244 sites for NAP and IBP under these conditions (Gu et al., 1994; Gu and Karthikeyan, 2005).

245 The sorption isotherms did not exhibit sorption maxima, indicating that sorption sites were not 246 saturated at the concentrations studied. The Freundlich isotherm model $\left(q_{i}=K_{f} c_{i}^{n}\right.$, where $K_{f}$ is 247 the Freundlich constant and $n$ is the Freundlich exponent) strongly fit the sorption isotherms $\left(\mathrm{R}^{2}\right.$ $248>0.90$ ). $K_{f}$ was higher for both compounds in A-horizon soils than in B-horizon soils (data not 249 shown); $n<1$ in all A-horizon soils and $n \cong 1$ in all B-horizon soils. When $n<1$, the isotherm 250 concaved downwards, indicating that as sorbate concentrations increased, the sorbates were 251 bound to the soil components with weaker free energies. This behavior is commonly observed in 252 sorption of polar organic solutes on charged surfaces (Chiou, 2003). When $n=1$, the isotherm 253 was linear, indicating constant sorption free energies at all sorbate concentrations 254 (Schwarzenbach et al., 2003). Such isotherms are common when sorption involves either 255 uncharged sorbent surfaces or nonpolar organic compounds. Since both NAP and IBP were 256 primarily anionic at the soil solution $\mathrm{pH}$, their $n$ values were more likely a reflection of the nature 257 of a sorbent that was low in OM and high in clay mineral and Fe oxide content. The solid-water 258 distribution coefficient $K_{d}\left(=q_{i} / c_{i}\right)$, calculated from the sorption isotherms data, decreased with 
259 increasing concentration in all A-horizon soils and was nearly constant in the B-horizon soils,

260 confirming the trends observed in the sorption isotherms. There were weak but positive linear

261 correlations between $K_{d}$ and $f_{\mathrm{OC}}$ and $K_{f}$ and $f_{\mathrm{OC}}$, indicating that both compounds preferentially

262 partitioned to soils with larger SOM content.

\section{3.2 Transformation products formed during soil sorption studies:}

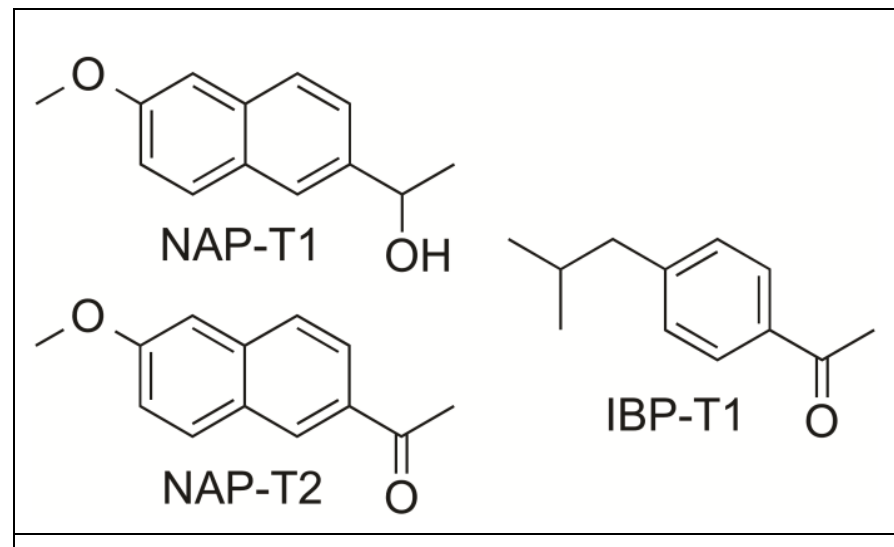

Figure 3. NAP and IBP transformation products. NAP-T2 and IBP-T1 were observed as soil transformation (ST) products; all three compounds were observed as photo transformation (PT) products.

During batch sorption experiments in A-horizon soils $\left(f_{\mathrm{OC}}=0.09\right)$, small amounts of NAP and

266 IBP transformation products were observed (NAP-T2 and IBP-T1, Fig. 3) which were identified

267 by APCI-LC-MS/MS (S1). NAP-T2 (2-acetyl-6-methoxynaphthalene) is the decarboxylated

268 ketone analog of NAP while IBP-T1 (4-isobutylacetophenone) is the same analog of IBP. These

269 transformation products were observed at significantly lower concentrations than the parent

270 compound - approximately $10^{5}$ and $10^{4}$ times lower than concentrations for NAP and IBP,

271 respectively, too low to impact sorption of the parent compounds - and were directly correlated 
272 with the equilibrium solution concentrations of the parent PhACs (Fig. 4). Transformation

273 products previously observed as the result of biodegradation of naproxen (Quintana et al., 2005;

274 Wojcieszynska et al., 2014) and ibuprofen (Matamoros et al., 2008) were not observed in this 275 study. IBP-T1 and NAP-T2 have been observed in other phototransformation studies

276 (DellaGreca et al., 2003; Jacobs et al., 2011; Marotta et al., 2013; Ruggeri et al., 2013). Toxicity

277 studies have shown these compounds, both aromatic ketones, to be more ecotoxic than the parent 278 PhACs (DellaGreca et al., 2003; Ruggeri et al., 2013), raising concerns about their production 279 during environmental processes.

280

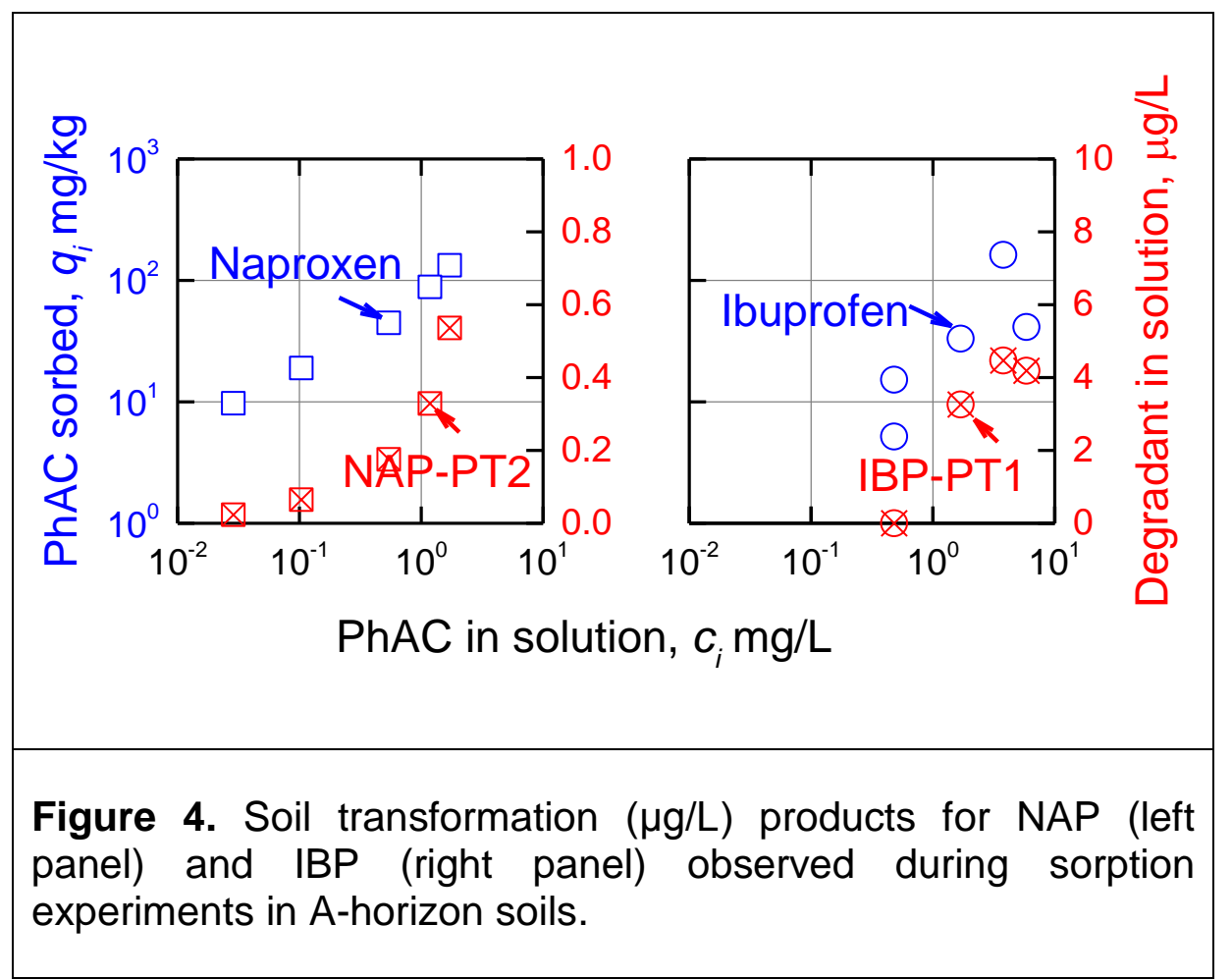


283 When exposed to simulated sunlight, naproxen (5 ppb) underwent relatively rapid direct solar 284 photodegradation following a pseudo-first order rate law (half-life, $\mathrm{t}_{1 / 2}=53 \mathrm{~min}$ ). Ibuprofen (50 285 ppb) was observed to photodegrade much more slowly, also following pseudo-first order kinetics $286\left(t_{1 / 2}=44 \mathrm{~h}\right)$. Both results were expected; NAP's absorption spectrum overlaps with the solar 287 spectrum (>290nm), promoting direct photodegradation, while IBP's spectrum does not overlap 288 (Fig. 5).

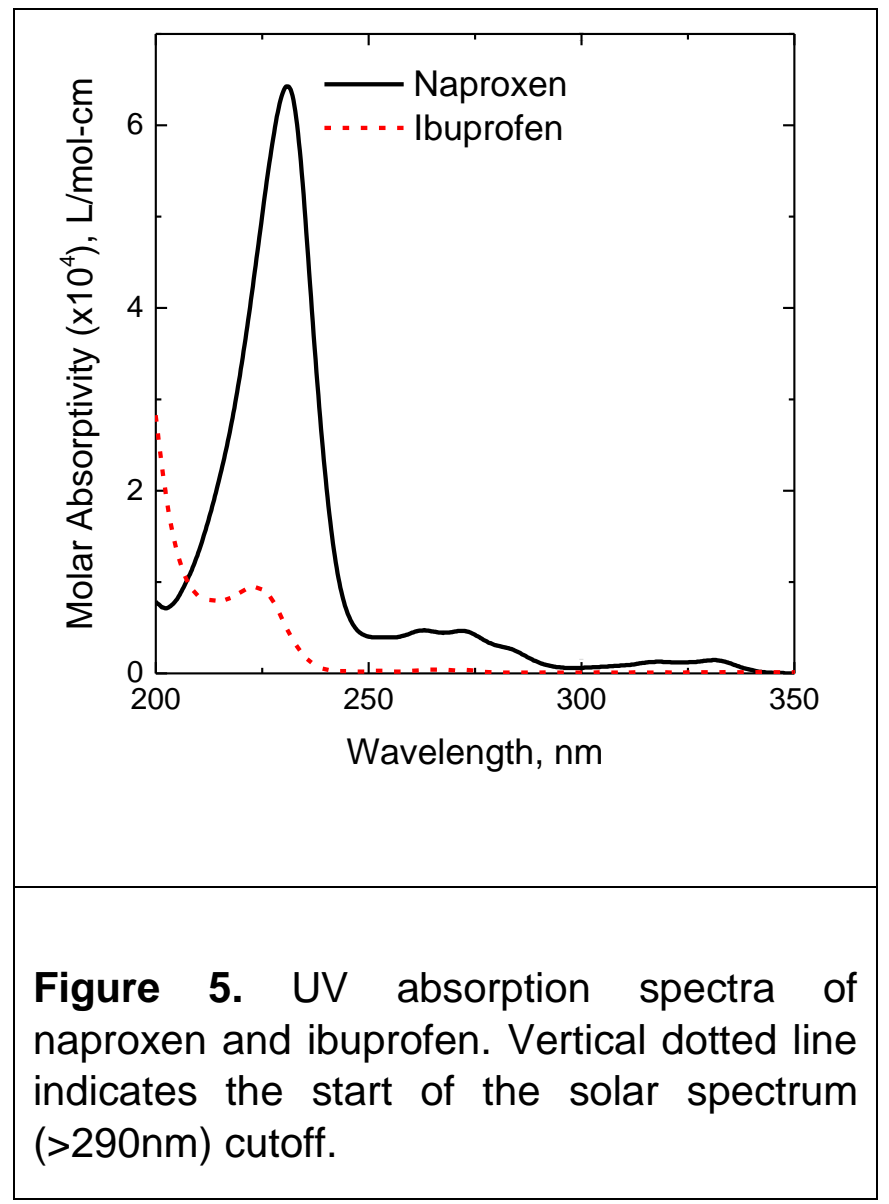
The addition of both SRFA and SRHA to NAP in aqueous solution $(\mathrm{pH}=7.0)$ resulted in an overall decrease NAP's rate of photodegradation (Fig. 5). The addition of $10 \mathrm{ppm}$ SRFA led to 292 an even slower rate $\left(t_{1 / 2}=4 \mathrm{~h}\right)$ than the addition of 25 ppm SRFA $\left(t_{1 / 2}=2 \mathrm{~h}\right)$, indicating the 
possible occurrence of competing photosensitization and photo inhibition. In the case of SRHA, the addition of both $10 \mathrm{ppm}$ and $25 \mathrm{ppm}$ both resulted in the same, slower rate $\left(\mathrm{t}_{1 / 2}=4 \mathrm{~h}\right)$. The degradation in dark control samples of each solution was observed to be negligible over this time 296 frame.

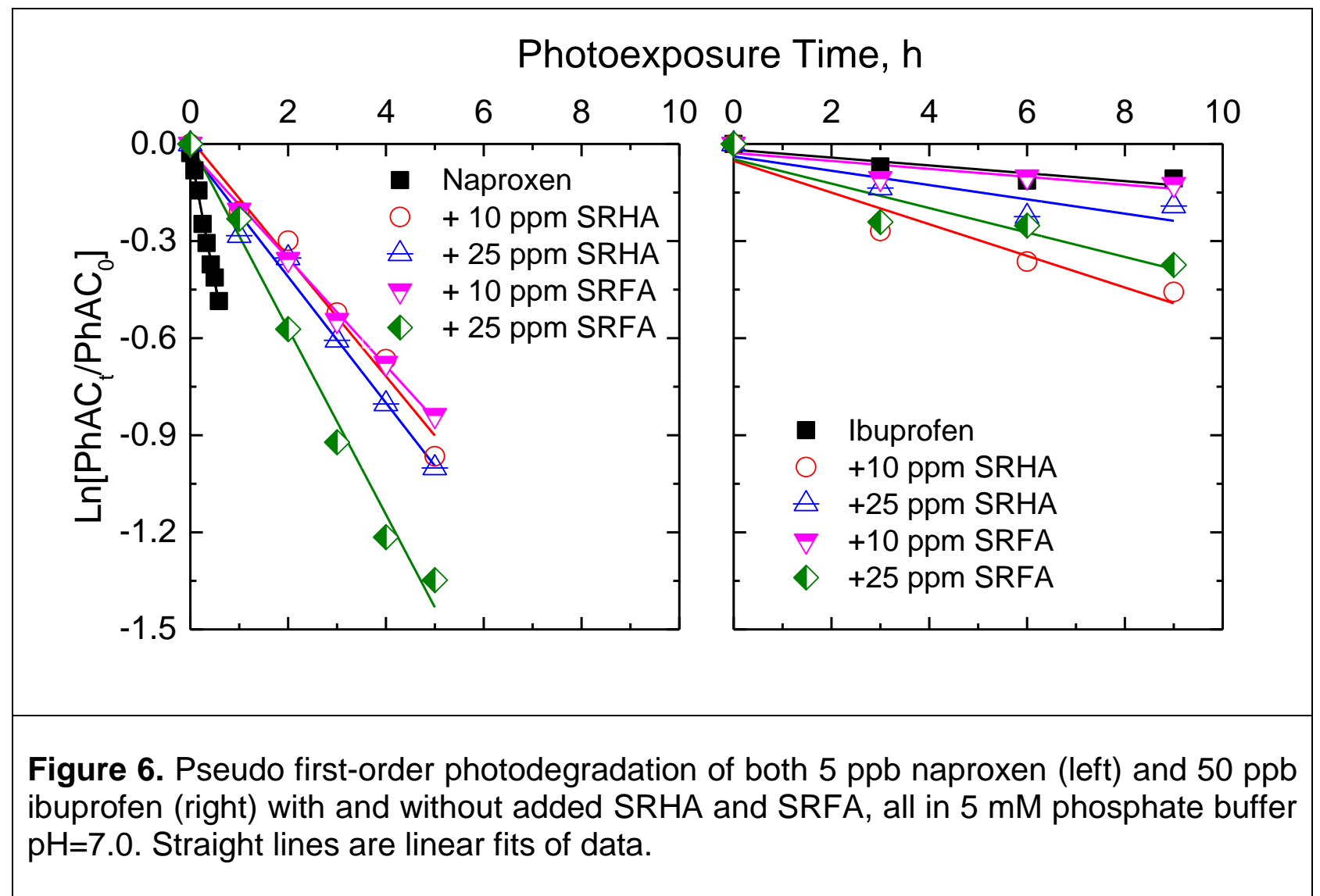

Additions of SRFA and SRHA to IBP solutions were observed to increase the photodegradation rate by one to three times over that of buffered IBP alone, indicating that DOM acted primarily as a photosensitizer and promoted indirect photodegradation (Fig. 6). A smaller concentration of SRHA (10 ppm) resulted in a higher rate of photodegradation $\left(t_{1 / 2}=15 \mathrm{~h}\right)$ than the higher $25 \mathrm{ppm}$ $\left(t_{1 / 2}=20 \mathrm{~h}\right)$ indicating the possibility of competing photosensitization and photo inhibition with more concentrated SRHA. The rates for both $10 \mathrm{ppm}$ and $25 \mathrm{ppm}$ SRFA were equal to each other 
304 and similar to the SRHA values $\left(\mathrm{t}_{1 / 2}=17 \mathrm{~h}\right)$. The degradation in dark control samples of each 305 solution was again observed to be negligible over this time frame.

\subsection{Transformation products formed during photoexposure studies}

307 Photodegradation of NAP was observed to produce two transformation products, the 308 decarboxylated alcohol analog 1-(6-methoxy-2-naphthyl) ethanol (NAP-T1) and the ketone 309 analog (NAP-T2) (Fig. 3). Both compounds have been reported to form during photoexposure as 310 a result of the decarboxylation of NAP followed by the formation of a radical, oxidation to NAP311 T1, and further oxidation to NAP-T2 (Musa and Eriksson, 2008).

312 A solution containing 50 ppb NAP with 10 ppm SRHA was also photoexposed under the same 313 conditions (ten times higher than the concentration exposed in Fig. 6, higher concentration was 314 required to quantify the transformation products). In this solution, NAP's half-life was observed 315 to be $5 \mathrm{~h}$, the same as that observed for $5 \mathrm{ppb}$ NAP with $10 \mathrm{ppm}$ SRHA. After $5 \mathrm{~h}$ of 316 photoexposure, the concentration of NAP-T1 formed was $4 \mathrm{ppb}$, or $8 \%$ of the original NAP 317 concentration, while the amount of NAP-T2 product formed was also $4 \mathrm{ppb}(8 \%)$, resulting in a 318 total $16 \%$ conversion of NAP to transformation products at the half life.

319 After up to $90 \mathrm{~h}$ of photoexposure, only one transformation product was observed for IBP (IBP-

320 T1, Fig. 3). This photochemical transformation of IBP has been reported to proceed through the 321 decarboxylation of IBP followed by the formation of a radical (Musa and Eriksson, 2007) and 322 subsequent oxidation. IBP-T1 is comparable to NAP-T2, as both are aromatic ketone analogs of 323 the parent PhAC. We did not observe the alcohol analog for IBP that is comparable to NAP-T2. 324 This was expected, as the isobutyl group on IBP is a much weaker electron donor than the ether 
325 linkage on NAP, causing the alcohol analog of IBP to be less stable than the NAP alcohol 326 analog.

327 A solution containing $500 \mathrm{ppb}$ IBP (ten times higher than the concentration exposed in Figure 6) 328 with 10 ppm SRHA was also photoexposed under the same conditions in order to quantify the 329 trace production of IBP-T1. At this concentration, IBP was observed to photodegrade at the same 330 rate as $50 \mathrm{ppb}$ IBP with $10 \mathrm{ppm}$ SRHA $\left(\mathrm{t}_{1 / 2}=15 \mathrm{~h}\right)$. After $15 \mathrm{~h}$ of photoexposure, the 331 concentration of IBP-T1 formed was $11 \mathrm{ppb}$, or $2 \%$ of the original IBP concentration. IBP-T1

332 directly absorbs sunlight and is therefore susceptible to direct photodegradation, unlike IBP. 333 However, IBP-T1 is structurally stable and has been observed by others in field samples. One 334 study determined that levels of up to $40 \mathrm{ng} / \mathrm{L}$ of this compound were present in sewage waters in 335 Sweden (Zorita et al., 2007) and $197 \mathrm{ng} / \mathrm{L}$ in the influent of a wastewater treatment plant (Manso 336 et al., 2014), indicating that it is indeed being formed and persisting in natural waters and 337 therefore potentially impacting the aquatic environment. As an aromatic ketone, this raises 338 concerns about ecotoxic risk.

341 While the transformation products observed here have been previously reported as 342 phototransformation (PT) products, in this study two of them (NAP-T2 and IBP-T1) were also 343 observed to be soil transformation (ST) products. The identity of each transformation product 344 was confirmed by comparison to standards using APCI-LC-MS/MS (see Supplementary Data). 
346 NAP and IBP were not exposed to light during soil sorption experiments and these

347 transformation products were observed only in A-horizon soils, those containing OM, but not in

348 B-horizon soils, which do not. The transformation process occurring in the soil is not known at

349 this time. Biological transformation of PhACs in soil is a possibility, as the soil was not sterilized

350 before sorption studies. However, the products of biological transformation processes are

351 generally more polar than the parent pharmaceutical (Boxall et al., 2004). For naproxen and 352 ibuprofen, reported biotransformation products include hydroxyl and carboxyl analogs

353 (Matamoros et al., 2008; Wojcieszynska et al., 2014). These products were not observed in this 354 study; the ketone and alcohol analogs observed here were less polar than the parent $\mathrm{PhAC}$. 355 Recent reports of dark hydroxyl radical formation in arctic soils (Page et al., 2013) indicate the 356 possibility that hydroxyl radical mediated transformation could contribute to soil transformation 357 as it does with DOM-mediated phototransformation.

358 These observations indicate that processes occurring in soil resulted in less polar, more ecotoxic 359 transformation products with more similarity to phototransformation products than to those 360 formed as a result of biological transformation. Further study is needed to determine the process 361 that transforms NAP and IBP into these products in soil.

\section{CONCLUSIONS}

363 Organic matter, both in soil and dissolved in aqueous solution, was observed to play an 364 important role in the sorption, photodegradation, and chemical transformation of both NAP and 365 IBP.

366 Sorption of both NAP and IBP was strong in soils that had higher OM content and weaker but 367 still significant in soils that were more clay- and Fe oxide-rich. This led to the conclusion that the 
368 aromatic moieties of the compounds were strongly interacting with aromatic fractions of natural

369 OM present in soils. The permanent negative charge in clay minerals was not observed to have

370 significantly contributed to sorption of these compounds.

371 Two soil transformation products were observed, NAP-T2 and IBP-T1. These transformation

372 products were observed in A-horizon soils, which have high OM contents. The processes leading

373 to this chemical transformation of NAP and IBP in soils is not known at this time.

374 NAP and IBP both underwent photodegradation in simulated sunlight. The half-life of IBP

375 photodegradation in all solutions was longer than that of NAP, indicating that IBP is more likely

376 to be persistent in surface waters than NAP. While the addition of SRHA and SRFA had an

377 overall inhibitory effect on the rate of NAP photodegradation, the IBP degradation rate was

378 observed to increase in the presence of DOM as indirect photodegradation was promoted.

379 Two PT products for NAP and one for IBP were identified: the two ketone analogs observed in 380 soil samples were also observed in photoexposed samples, along with an alcohol analog of 381 naproxen. Higher amounts of these products were observed in photoexposed solutions than in 382 soil samples.

383 The combination of the sorption, photodegradation, and transformation results led to the 384 conclusion that $\mathrm{OM}$ is an important factor in the environmental fate of both NAP and IBP. More 385 studies of the processes involved in soil transformation are needed, as the products identified 386 here have been observed to have higher ecotoxicity than the parent PhACs. These combined 387 results indicate that the environmental processes occurring once these PhACs enter the 388 environment can have a notable impact on the quality of the water resources in our communities. 
390 The authors would like to acknowledge Dr. William J. Cooper of University of California-Irvine 391 for his mentorship and many helpful discussions, Will Vesely for his help with ST experiments, 392 and Dr. Robert Nusbaum of College of Charleston for assistance with characterization of soil. 393 This material is based on work supported by the National Science Foundation under grants CHE394 1429308, CBET-1233266, CHE-1229559 and CHE-0821426 and the Howard Hughes Medical 395 Institute Precollege and Undergraduate Science Education Program. Support was also provided 396 Undergraduate Research and Creative Activities (URCA) at the College of Charleston. 
Barnes KK, Kolpin DW, Furlong ET, Zaugg SD, Meyer MT, Barber LB. A national reconnaissance of pharmaceuticals and other organic wastewater contaminants in the United States - I) Groundwater. Science of The Total Environment 2008; 402: 192-200.

Benotti MJ, Trenholm RA, Vanderford BJ, Holady JC, Stanford BD, Snyder SA. Pharmaceuticals and Endocrine Disrupting Compounds in U.S. Drinking Water. Environmental Science \& Technology 2008; 43: 597-603.

Biehl LL, Stoner E. Reflectance properties of soils. Adv. Agron. 1985; 38: 1-44.

Boreen AL, Arnold WA, McNeill K. Photochemical fate of sulfa drugs in the aquatic environment: Sulfa drugs containing five-membered heterocyclic groups. Environmental Science \& Technology 2004; 38: 3933-3940.

Boxall ABA, Sinclair CJ, Fenner K, Kolpin D, Maud SJ. When synthetic chemicals degrade in the environment. Environmental Science \& Technology 2004; 38: 368A-375A.

Bradley PM, Barber LB, Duris JW, Foreman WT, Furlong ET, Hubbard LE, et al. Riverbank filtration potential of pharmaceuticals in a wastewater-impacted stream. Environmental Pollution 2014; 193: 173-180.

Chiou CT. Contaminant Sorption to Soils and Natural Solids. Partition and Adsorption of Organic Contaminants in Environmental Systems. John Wiley \& Sons, Inc., 2003, pp. 106-213.

Clark RN. Spectroscopy of Rocks and Minerals, and Principles of Spectroscopy. In: Rencz AN, editor. Manual of Remote Sensing, Volume 3, Remote Sensing for the Earth Sciences. 3. John Wiley and Sons, New York, 1999, pp. 3-58.

Clark RN, Swayze GA, Wise R, Livo KE, Hoefen TM, Kokaly RF, et al. USGS Digital Spectral Library splib05a, Open File Report 03-395. Open File Report 03-395. U.S. Geological Survey Denver, CO, 2003.

Cooper WJ, Zika RG, Petasne RG, Fischer AM. Sunlight-Induced Photochemistry of Humic Substances in Natural-Waters - Major Reactive Species. Acs Symposium Series 1989; 219: 333-362.

Cunningham VL. Special Characteristics of Pharmaceuticals Related to Environmental Fate. In: Kümmerer K, editor. Pharmaceuticals in the Environment. Springer Berlin Heidelberg, 2008, pp. 23-34.

Daughton CG, Ternes TA. Pharmaceuticals and personal care products in the environment: agents of subtle change? Environ. Health Perspect. 1999; 107: 907-938.

DellaGreca M, Brigante M, Isidori M, Nardelli A, Previtera L, Rubino M, et al. Phototransformation and ecotoxicity of the drug Naproxen-Na. Environmental Chemistry Letters 2003; 1: 237-241.

Dodgen LK, Li J, Wu X, Lu Z, Gan JJ. Transformation and removal pathways of four common PPCP/EDCs in soil. Environmental Pollution 2014; 193: 29-36.

Fatta-Kassinos D, Vasquez MI, Kummerer K. Transformation products of pharmaceuticals in surface waters and wastewater formed during photolysis and advanced oxidation processes - Degradation, elucidation of byproducts and assessment of their biological potency. Chemosphere 2011; 85: 693-709.

Figueroa RA, MacKay AA. Sorption of Oxytetracycline to Iron Oxides and Iron Oxide-Rich Soils. Environmental Science \& Technology 2005; 39: 6664-6671. 
Focazio MJ, Kolpin DW, Barnes KK, Furlong ET, Meyer MT, Zaugg SD, et al. A national reconnaissance for pharmaceuticals and other organic wastewater contaminants in the United States - II) Untreated drinking water sources. Science of The Total Environment 2008; 402: 201-216.

Food and Drug Administration US. Motrin Ibuprofen Tablets, USP, accessed at http://www.accessdata.fda.gov/drugsatfda_docs/label/2007/017463s105lbl.pdf, 2007.

Gee GW, Or D. 2.4 Particle-Size Analysis. In: Dane JH, Topp CG, editors. Methods of Soil Analysis: Part 4 Physical Methods. Soil Science Society of America, 2002, pp. 255-293.

Gu B, Schmitt J, Chen Z, Liang L, McCarthy JF. Adsorption and desorption of natural organic matter on iron oxide: mechanisms and models. Environmental Science \& Technology 1994; 28: 38-46.

Gu C, Karthikeyan KG. Sorption of the Antimicrobial Ciprofloxacin To Aluminum and Iron Hydrous Oxides. Environmental Science \& Technology 2005; 39: 9166-9173.

Guerard JJ, Miller PL, Trouts TD, Chin YP. The role of fulvic acid composition in the photosensitized degradation of aquatic contaminants. Aquatic Sciences 2009; 71: 160169.

Halling-Sorenson B, Nielsen SN, Lanzky PF, Ingerslev F, Lützhoft HC, Jorgensen SE. Occurrence, fate, and effects of pharmaceutical substances in the environment - a review. Chemosphere 1998; 36: 357-393.

Jacobs LE, Fimmen RL, Chin YP, Mash HE, Weavers LK. Fulvic acid mediated photolysis of ibuprofen in water. Water Research 2011; 45: 4449-4458.

Jelić A, Petrović M, Barceló D. Pharmaceuticals in Drinking Water. In: Barceló D, editor. Emerging Organic Contaminants and Human Health. Springer Berlin Heidelberg, 2012, pp. 47-70.

Khetan SK, Collins TJ. Human Pharmaceuticals in the Aquatic Environment: A Challenge to Green Chemistry. Chemical Reviews 2007; 107: 2319-2364.

Kleber M, Sollins P, Sutton R. A conceptual model of organo-mineral interactions in soils: selfassembly of organic molecular fragments into zonal structures on mineral surfaces. Biogeochemistry 2007; 85: 9-24.

Kolpin DW, Furlong ET, Meyer MT, Thurman EM, Zaugg SD, Barber LB, et al. Pharmaceuticals, hormones, and other organic wastewater contaminants in U.S. streams, 1999-2000: A national reconnaissance. Environ. Sci. Technol. 2002; 36: 1202-1211.

Lapworth DJ, Baran N, Stuart ME, Ward RS. Emerging organic contaminants in groundwater: A review of sources, fate and occurrence. Environmental Pollution 2012; 163: 287-303.

Li JY, Ye QF, Gan J. Degradation and transformation products of acetaminophen in soil. Water Research 2014; 49: 44-52.

Li WC. Occurrence, sources, and fate of pharmaceuticals in aquatic environment and soil. Environmental Pollution 2014; 187: 193-201.

Loffler D, Rombke J, Meller M, Ternes TA. Environmental fate of pharmaceuticals in water/sediment systems. Environ. Sci. Technol. 2005; 39: 5209-5218.

Maiss M, Steele LP, Francey RJ. Sulfur hexafluoride--a powerful new atmospheric tracer. Atmos. Environ. 1996; 30: 1621-1629.

Manso J, Larsson E, Jonsson JA. Determination of 4'-isobutylacetophenone and other transformation products of anti-inflammatory drugs in water and sludge from five wastewater treatment plants in Sweden by hollow fiber liquid phase microextraction and gas chromatography-mass spectrometry. Talanta 2014; 125: 87-93. 
Marotta R, Spasiano D, Di Somma I, Andreozzi R. Photodegradation of naproxen and its photoproducts in aqueous solution at $254 \mathrm{~nm}$ : A kinetic investigation. Water Research 2013; 47: 373-383.

Matamoros V, Bayona JM. Elimination of Pharmaceuticals and Personal Care Products in Subsurface Flow Constructed Wetlands. Environ. Sci. Technol. 2006; 40: 5811-5816.

Matamoros V, Caselles-Osorio A, Garcia J, Bayona JM. Behaviour of pharmaceutical products and biodegradation intermediates in horizontal subsurface flow constructed wetland. A microcosm experiment. Science of the Total Environment 2008; 394: 171-176.

Musa KAK, Eriksson LA. Theoretical study of ibuprofen phototoxicity. Journal of Physical Chemistry B 2007; 111: 13345-13352.

Musa KAK, Eriksson LA. Theoretical Study of the Phototoxicity of Naproxen and the Active Form of Nabumetone. Journal of Physical Chemistry A 2008; 112: 10921-10930.

Oades JM. An Introduction to Organic Matter in Mineral Soils. In: Dixon JB, Weed SB, editors. Minerals in Soil Environments. Soil Science Society of America, 1989, pp. 89-159.

Page SE, Kling GW, Sander M, Harrold KH, Logan JR, McNeill K, et al. Dark Formation of Hydroxyl Radical in Arctic Soil and Surface Waters. Environmental Science \& Technology 2013; 47: 12860-12867.

Pal A, Gin KYH, Lin AYC, Reinhard M. Impacts of emerging organic contaminants on freshwater resources: Review of recent occurrences, sources, fate and effects. Science of the Total Environment 2010; 408: 6062-6069.

Quintana JB, Weiss S, Reemtsma T. Pathway's and metabolites of microbial degradation of selected acidic pharmaceutical and their occurrence in municipal wastewater treated by a membrane bioreactor. Water Research 2005; 39: 2654-2664.

Ruggeri G, Ghigo G, Maurino V, Minero C, Vione D. Photochemical transformation of ibuprofen into harmful 4-isobutylacetophenone: Pathways, kinetics, and significance for surface waters. Water Research 2013; 47: 6109-6121.

Runkel R, Chaplin M, Boost G, Segre E, Forchielli E. Absorption, Distribution, Metabolism, and Excretion of Naproxen in Various Laboratory Animals and Human Subjects. J. Pharm. Sci. 1972; 61: 703-708.

Schwarzenbach RP, Gschwend PM, Imboden DM. Environmental organic chemistry. New York, NY: Wiley, 2003.

Snyder SA, Westerhoff P, Yoon Y, Sedlak DL. Pharmaceuticals, Personal Care Products, and Endocrine Disruptors in Water: Implications for the Water Industry. Environmental Engineering Science 2003; 20: 449-469.

Stumm W, Morgan JJ. Aquatic chemistry. New York, NY: Wiley-Interscience, 1996.

Sutton R, Sposito G. Molecular Structure in Soil Humic Substances: The New View. Environmental Science \& Technology 2005; 39: 9009-9015.

Swift RS. Organic Matter Characterization. In: Sparks DL, Page AL, Helmke PA, Loeppert RH, editors. Methods of Soil Analysis Part 3-Chemical Methods. Soil Science Society of America, American Society of Agronomy, 1996, pp. 1011-1069.

Ternes TA. Occurrence of drugs in German sewage treatment plants and rivers. Water Research 1998; 32: 3245-3260.

Ternes TA, Joss A, Siegrist H. Scrutinizing pharmaceuticals and personal care products in wastewater treatment. Environ. Sci. Technol. 2004; 38: 377A-400A.

Thiele-Bruhn S. Pharmaceutical antibiotic compounds in soils - a review. Journal of Plant Nutrition and Soil Science 2003; 166: 145-167. 
Thomas GW. Soil pH and Soil Acidity. In: Sparks DL, Page AL, Helmke PA, Loeppert RH, editors. Methods of Soil Analysis Part 3-Chemical Methods. Soil Science Society of America, American Society of Agronomy, 1996, pp. 475-490.

Tolls J. Sorption of Veterinary Pharmaceuticals in Soils: A Review. Environ. Sci. Technol. 2001; 35: 3397-3406.

Tülp HC, Fenner K, Schwarzenbach RP, Goss K-U. pH-Dependent Sorption of Acidic Organic Chemicals to Soil Organic Matter. Environmental Science \& Technology 2009; 43: 9189 9195.

Vulava VM, Kretzschmar R, Rusch U, Grolimund D, Westall JC, Borkovec M. Cation competition in a natural subsurface material: Modeling of sorption equilibria. Environ. Sci. Technol. 2000; 34: 2149-2155.

Walse SS, Morgan SL, Kong L, Ferry JL. Role of dissolved organic matter, nitrate, and bicarbonate in the photolysis of aqueous fipronil. Environmental Science \& Technology 2004; 38: 3908-3915.

White JL, Roth CB. Infrared Spectrometry. In: Klute A, editor. Methods of Soil Analysis: Part 1-Physical and Mineralogical Methods. Soil Science Society of America, American Society of Agronomy, 1986, pp. 291-330.

Wojcieszynska D, Domaradzka D, Hupert-Kocurek K, Guzik U. Bacterial degradation of naproxen - Undisclosed pollutant in the environment. Journal of Environmental Management 2014; 145: 157-161.

Yamamoto H, Nakamura Y, Moriguchi S, Nakamura Y, Honda Y, Tamura I, et al. Persistence and partitioning of eight selected pharmaceuticals in the aquatic environment: Laboratory photolysis, biodegradation, and sorption experiments. Water Research 2009; 43: 351-362.

$\mathrm{Yu}$ JT, Bouwer EJ, Coelhan M. Occurrence and biodegradability studies of selected pharmaceuticals and personal care products in sewage effluent. Agricultural Water Management 2006; 86: 72-80.

Zhang $\mathrm{H}$, Huang $\mathrm{C}-\mathrm{H}$. Adsorption and oxidation of fluoroquinolone antibacterial agents and structurally related amines with goethite. Chemosphere 2007; 66: 1502-1512.

Zorita S, Barri T, Mathiasson L. A novel hollow-fibre microporous membrane liquid-liquid extraction for determination of free 4-isobutylacetophenone concentration at ultra trace level in environmental aqueous samples. Journal of Chromatography A 2007; 1157: 3037. 